\title{
Synthesis of Cds Nanoparticle by the Hydrothermal Method and the Contribution in Different Biological Uses
}

\author{
HOUCINE LABIADH $^{1}$ ALI MEZNI ${ }^{2}$, NOUHA LOUDHAIEF ${ }^{1}$, \\ MOULDIZOUAOUI $^{1}$ and MOHAMED BEN SALEM ${ }^{1}$
}

${ }^{1}$ Laboratory of Physics of Materials - Structure and Properties, Department of Physics,

${ }^{2}$ Laboratoire de Biosurveillance de l'Environnement Département de Biologie. Faculty of Sciences of Bizerte, University of Carthage, 7021 Zarzouna, Tunisia

labiadhhoucine1983@gmail.com

Received 7 Novembre 2018 / Accepted 3 December 2018

\begin{abstract}
Cadmium sulfide CdS nanoparticles were synthesized in aqueous medium at $\mathrm{pH}$ constant, the obtained nanoparticles has been characterized by x-ray diffraction (XRD) and transmission electron microscopy (TEM). Cadmium sulfide nanoparticles were screened for their antibacterial and tested for antioxidant activity using 1,1-diphenyl-2-picrylhydrazyl (DPPH), hydroxyl radical $\left(\mathrm{OH}^{\cdot}\right)$ and hydrogen peroxide $\left(\mathrm{H}_{2} \mathrm{O}_{2}\right)$ scavenging activity, ferric reducing power (FRP) assay and ferrous ion chelating (FIC) methods. The sizes of the crystallites were estimated to $12 \mathrm{~nm}$ using the Debye-Scherrer formula based on the XRD data. Transmission electron microscopy (TEM) results indicate that the CdS nanocrystals distribute uniformly and the size is $12 \mathrm{~nm}$. The obtained CdS quantum dots present an antioxidant activity especially in oxido reduction power. It was found that $\mathrm{CdS}$ nanoparticles showed relatively higher antioxidant activities that this nanomaterial' scan react at the interface with the life entities.
\end{abstract}

Keywords: Nanoparticles, Semiconductors, Antioxidant activity

\section{Introduction}

The semiconductor nanoparticles also called quantum dots (QDs) have been characterized by sizes generally inferior to $100 \mathrm{~nm}$. Due to this small size, they exhibit specific properties different from those of the corresponding bulk materials ${ }^{1-3}$. The interesting and sometimes unexpected properties of nanoparticles are therefore largely due to the large surface area of the material. The synthesis and properties of II-VI semiconductor quantum dots (QDs) have been extensively investigated over the last 30 years. The reason for this seems to be their special optical and electronic properties which arise from the quantum confinement of electrons and the large surface area ${ }^{4-12}$. The semiconducting nanocrystals of CdS are one of the more prominently studied and reported QDs for various applications. In bulk form, the CdS crystalisa hexagonal Wurtzite type structure with band gap energy Eg of $2.42 \mathrm{eV}^{13}$. 
In absence of any surface passivation, most of the nanoparticle systems undergo aggregation leading to an impact on the optical properties. Thus, it is of paramount significance to develop methods for the surface passivation of nanoparticles. Organic stabilizers have been the most frequently reported capping agent for the above purpose ${ }^{14}$. Apart from maintaining the desired size distribution, the capping with stabilizers provides specific functional groups that may be exploited for various biological labeling ${ }^{15}$. In particular, CdS have been extensively studied due to their potential applications in several technological areas such as solar photovoltaic cells, nano bar codes, field effect transistors, light emitting diodes, photocatalysis and in vivo biomedical detection fluorescent tags in biology and the development of chemical and biological sensors ${ }^{15-18}$.

In this context, the present study was focused on the contribution of CdS nanoparticles in biological uses, for that, nanoparticles has been synthesized and structurally characterized before been used in the in vitro evaluation of their antioxidant activities using 1,1-diphenyl2-picrylhydrazyl (DPPH), hydroxyl radical $(\mathrm{OH}$.) scavenging activity, ferric reducing power (FRP) assay and ferrous ion chelating (FIC). The study has been reinforced by screening in vivo tests for inactivation profiling with bacteria and fungus selected species.

\section{Experimental}

Cadmium chloride hydrate $\left(\mathrm{CdCl}_{2} \cdot \mathrm{H}_{2} \mathrm{O}, 98 \%\right)$, thiourea $\left(\mathrm{CH}_{4} \mathrm{~N}_{2} \mathrm{~S}, \geq 99 \%\right)$ propanoic acid $\left(\mathrm{C}_{3} \mathrm{H}_{6} \mathrm{O}_{2}, \geq 99.5 \%\right)$ and sodium hydroxide solution $(\mathrm{NaOH})$. All solutions were prepared using distilled water as the solvent.

\section{Synthesis of CdS nanoparticale}

CdS nanoparticles are prepared as follows. $5 \mathrm{~mL}$ of $0.1 \mathrm{M} \mathrm{CdCl}_{2} \cdot \mathrm{H}_{2} \mathrm{O}$ and $20 \mathrm{~mL}$ of $0.1 \mathrm{M}$ $\mathrm{C}_{3} \mathrm{H}_{6} \mathrm{O}_{2}$ were combined. The $\mathrm{pH}$ of this solution was adjusted to 10 using $2 \mathrm{M} \mathrm{NaOH}$. Next, $4.5 \mathrm{~mL}$ of $0.1 \mathrm{M} \mathrm{CH}_{4} \mathrm{~N}_{2} \mathrm{~S}$ were quickly injected into the solution. The result precursor mixture was stirred at room temperature for $24 \mathrm{~h}$, placed into a Teflon lined autoclave and finally subjected at $180{ }^{\circ} \mathrm{C}$ for $7 \mathrm{~h}$. The nanocrystals were collected by centrifugation, washed 3 times with ethanol and then dried in air at $80{ }^{\circ} \mathrm{C}$.

\section{Characterizations}

We have examined the structure, the average particle sizes and the phase composition of the resulting product by powder XRD using a Philips 1710 diffractometer with $\mathrm{CuK}_{\alpha}$ radiation and FEI Tecnai $\mathrm{G}_{2}$ transmission electron microscopy. The particles morphology study was carried out using FEI Tecnai G2 Transmission electron microscope (TEM) operating at $200 \mathrm{Kv}$.

\section{Results and discussion}

\section{Structural characterization: XRD and TEM}

$\mathrm{XRD}$ is a very important experimental technique that has long been used to address all issues related to the crystal structure of solids, including lattice constants and geometry, identification of unknown materials etc., Figure (1-a) shown the powder x-ray diffraction pattern of pure CdS nanoparticle. The diffraction peaks positioned at $2 \theta$ values of $24.91^{\circ}$, $26.57^{\circ}, 28.25^{\circ}, 36.47^{\circ}, 43.87^{\circ}, 48.047$ and $52.1^{\circ}$ match well with hexagonal wurtzite phase of CdS (JCPDS card no.89-2944) and can be indexed respectively to the $\left(\begin{array}{lll}1 & 0 & 0\end{array}\right),\left(\begin{array}{lll}0 & 0 & 2\end{array}\right)$, (101), (102), (110), (103) and (112) crystal planes. The average sizes of the CdS nanoparticles were estimated using the Debye-Scherrer formula ${ }^{19}$. 


$$
D=\frac{0.9 \lambda}{\beta \cos \theta}
$$

Where $\lambda$ is the $\mathrm{x}$-ray wavelength in nanometer, $\beta$ is the peak width of the diffraction peak profile at half maximum height in $2 \theta$ axis and $\theta$ is the Bragg angle. The average crystal size in semiconductor nano-sized CdS particles obtained from Scherrer formula equation is $10 \mathrm{~nm}$. According to the Figure 1, the lattice parameters of CdS with hexagonal structure are $\mathrm{a}=4.121 \AA$ and $\mathrm{c}=6.682$, which is in good agreement with the TEM measurements.

Figure (1-b) shows TEM images of CdS nanoparticles. As can be seen, all nanocrystals are nearly monodispersed with spherical or oval shape. The average diameters of the CdS were determined to be $12 \mathrm{~nm}$, based on statistical analyses of more than 100 nanoparticles in a region (Figure (1-b)).
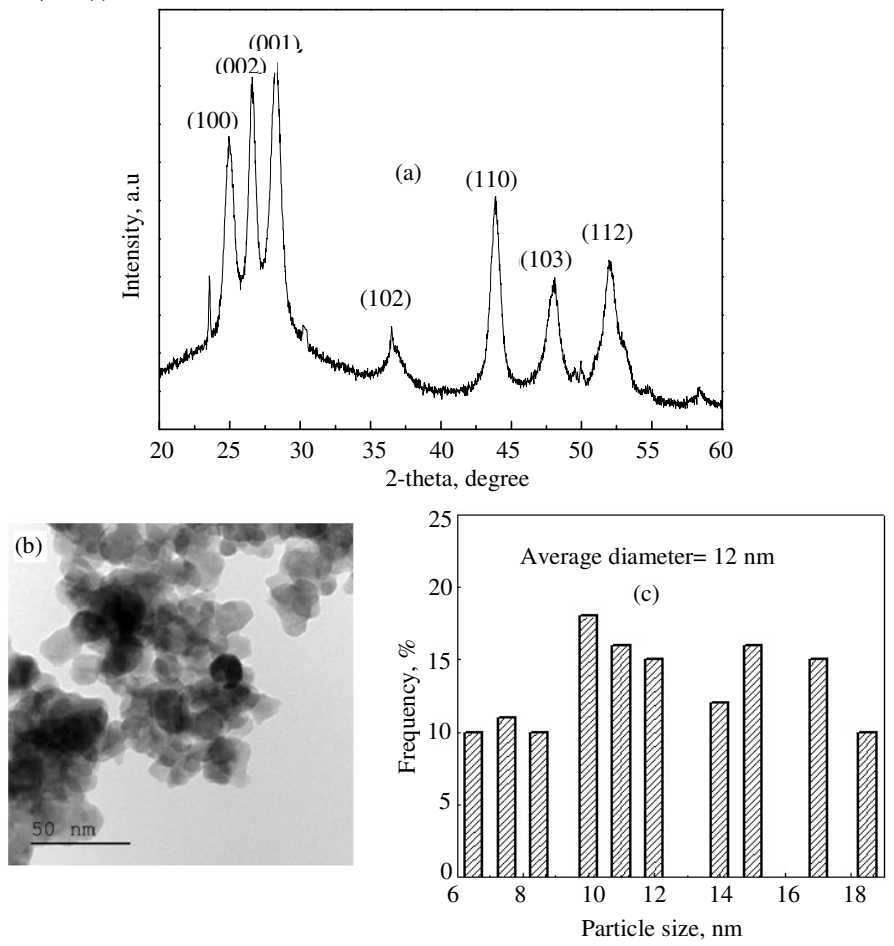

Figure 1. (a) XRD pattern, (b) TEM and (c) the corresponding size distribution of the nanocrystal $\mathrm{CdS}$

\section{In vitro antioxidant activity}

Antioxidants are used to prevent the formation of reactive oxygen species (ROS) as HO•, $\mathrm{H}_{2} \mathrm{O}_{2}$ and $\mathrm{NO}$, which are generated in living organisms during metabolism ${ }^{20}$. Excessive amounts of ROS are harmful because they can initiate biomolecular oxidations which lead to cell injury and death and create oxidative stress which results in numerous diseases and disorders such as cancer, diabetes, mycocardial infarction, stroke, etc $^{21,22}$.

The objective of this study was to evaluate the antioxidant activity of new compound $\mathrm{Cd}-\mathrm{S}$. The antioxidant properties were determined via the DPPH radical scavenging, the ABTS radical scavenging, ferric reducing power (FRP), hydroxyl radical scavenging and ferrous ion chelating activity (FIC). 


\section{$D P P H$ radical scavenging activity}

The DPPH free-radical scavenging activity: the hydrogen atom or electron donation abilities were measured by the bleaching of a purple colored methanol solution of DPPH. The freeradical scavenging activity of the various concentrations of new compound $(\mathrm{Cd}-\mathrm{S})$ and ascorbic acid was measured with the stable radical diphenylpicrylhydrazyl (DPPH) in terms of radical scavenging activity. $3 \mathrm{~mL}$ of DPPH (in methanol) was added to $100 \mu \mathrm{L}$ of compound (dissolved in methanol), at different concentrations (1-0.2 mg/mL). After incubation $30 \mathrm{~min}$, the absorbance was measured at $517 \mathrm{~nm}$ according to a described procedure $^{23}$. Ascorbic acid was used as a positive control. Each study corresponded to three experiments, performed in duplicate. The scavenging activity was estimated based on the percentage of DPPH radicals scavenged by the following formula:

$\%$ Scavenging $=\left[\left(\mathrm{A}_{0}-\mathrm{A}_{\mathrm{s}}\right) / \mathrm{A}_{0}\right] \times 100$ where $\mathrm{A}_{0}$ is absorption of control, $\mathrm{AS}$ is absorption of tested extract solution.

The result showed remarkable scavenging activity was presented in Figure 2. The compound had the highest capacity of scavenging DPPH radicals with percentage of inhibition $45.05 \pm 1.85 \%$ (IC50=0.994 mg/mL) at the concentration $(1 \mathrm{mg} / \mathrm{mL}$ ) and compared with ascorbic acid at the same concentration $66.43 \pm 0.83 \%$ (IC50=0.67 mg/mL).

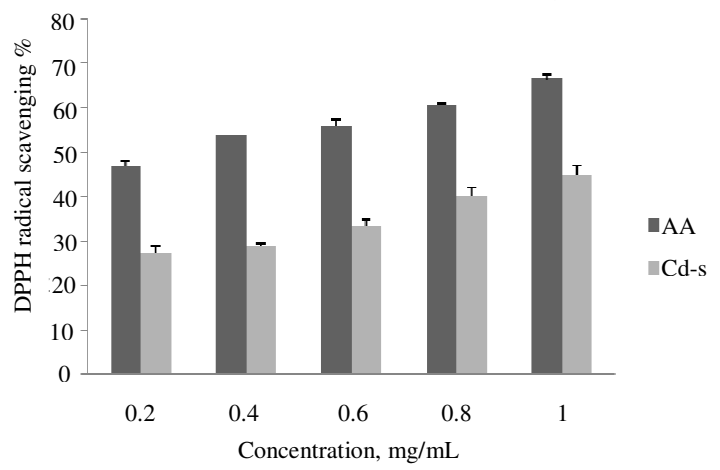

Figure 2. DPPH radical scavenging activity: tested compound (Cd-S), AA: ascorbic acid)

\section{ABTS radical scavenging activity}

ABTS assay was performed according to the protocol ${ }^{24}$. The stock solution was prepared by mixing equal volumes of $7 \mathrm{mM}$ ABTS solution and $2.45 \mathrm{mM}$ potassium persulfate solution followed by incubation for $12 \mathrm{~h}$ at room temperature in the dark to yield a dark-colored solution containing ABTS $\bullet+$ radicals. Working solution was prepared freshly before each assay by diluting the stock solution by mixing of stock solution to $50 \%$ methanol. Free radical scavenging activity was assessed by mixing $300 \mu \mathrm{L}$ of compound (Cd-S) at various concentrations $(1-0.2 \mathrm{mg} / \mathrm{mL}$ in methanol) with $3.0 \mathrm{~mL}$ of ABTS working standard. The absorbance was measured at $734 \mathrm{~nm}$. Data for each assay was recorded in triplicate. Ascorbic acid was used as positive controls. The scavenging activity was estimated based on the percentage of ABTS radicals scavenged by the following formula:

$\%$ Scavenging $=[(\mathrm{A} 0-\mathrm{As}) / \mathrm{A} 0] \times 100$, where $\mathrm{A} 0$ is absorption of control, AS is absorption of tested compound.

Differences for the ABTS $\bullet^{+}$(2,2-azobis-(3-ethylbenzothiozoline-6-sulphonic acid) radical scavenging capacities of each sample was recorded in Figure 3. The compound $(\mathrm{Cd}-\mathrm{S})$ was presented the highest capacity of scavenging at the high concentration $(1 \mathrm{mg} / \mathrm{mL})$ 
with Value $55.92 \pm 1.65 \%$ (IC50=0.768) and ascorbic acid at the same concentration $69.38 \pm 0.214 \%\left(\mathrm{IC}_{50}=0.778\right)$.

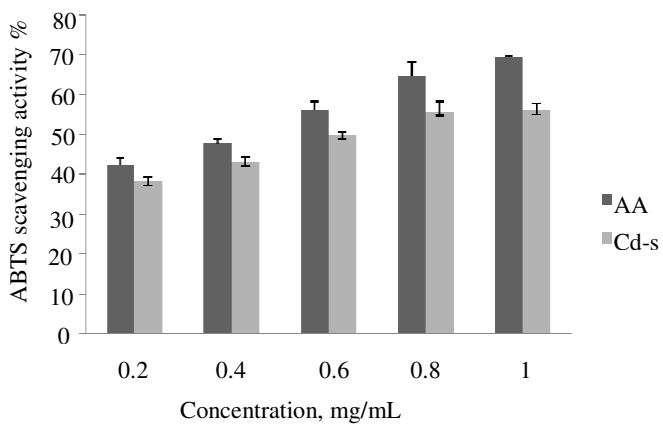

Figure 3. ABTS radical scavenging ability: tested compound (Cd-S), AA: ascorbic acid)

\section{Hydroxyl radical scavenging ability}

The effect of compound on hydroxyl radicals was assayed by using the deoxyribose method described by Halliwell and Gutteridge ${ }^{25}$. 2-Deoxyribose is degraded on exposure to hydroxyl radicals generated by Fenton's reaction. The compound (Cd-S) and ascorbic acid (AA) was prepared in methanol. The reaction mixture contained $450 \mu \mathrm{L}$ of $0.2 \mathrm{M}$ sodium phosphate buffer (pH 7.0), $150 \mu \mathrm{L}$ of $10 \mathrm{mM}$ 2-deoxyribose, $150 \mu \mathrm{L}$ of $10 \mathrm{mM} \mathrm{FeSO}_{4}$-EDTA, $150 \mu \mathrm{L}$ of $10 \mathrm{mM} \mathrm{H}_{2} \mathrm{O}_{2}, 525 \mu \mathrm{L}$ of $\mathrm{H}_{2} \mathrm{O}$ and $75 \mu \mathrm{L}$ of sample solution $(0.2-1 \mathrm{mg} / \mathrm{mL})$. The reaction was started by the addition of $\mathrm{H}_{2} \mathrm{O}_{2}$. After incubation at $37{ }^{\circ} \mathrm{C}$ for $30 \mathrm{~min}$, the reaction was stopped by adding $750 \mu \mathrm{L}$ of $2.8 \%$ trichloroacetic acid and $750 \mu \mathrm{L}$ of $1 \%$ TBA in $50 \mathrm{mM} \mathrm{NaOH}$, the solution was boiled for $10 \mathrm{~min}$ and then cooled in water. The absorbance of the solution was measured at $520 \mathrm{~nm}$. Ascorbic acid $(0.2-1 \mathrm{mg} / \mathrm{mL})$ was used as a positive control. The ability to scavenge the hydroxyl radical was calculated using the following equation:

Percentage $\mathrm{OH}$ radical scavenging ability $(\%)=[($ Abs cont-Abs test $) /$ Abs cont $] \times 100$ Abs cont $=$ absorbance of the control (reacting mixture without the test sample) and Abs test $=$ absorbance of reacting mixture with the test sample.

The results were summarized in the Figure 4 demonstrated that the most effective for hydroxyl radical scavenging activity followed at highest concentration $(1 \mathrm{mg} / \mathrm{mL}) 34.46 \pm$ $1.13 \%\left(\mathrm{IC}_{50}=1.24\right)$ and compared with ascorbic acid at the same concentration $(1 \mathrm{mg} / \mathrm{mL})$ the percentage of inhibition was $55.28 \pm 1.86 \%\left(\mathrm{IC}_{50}=0.85\right)$.

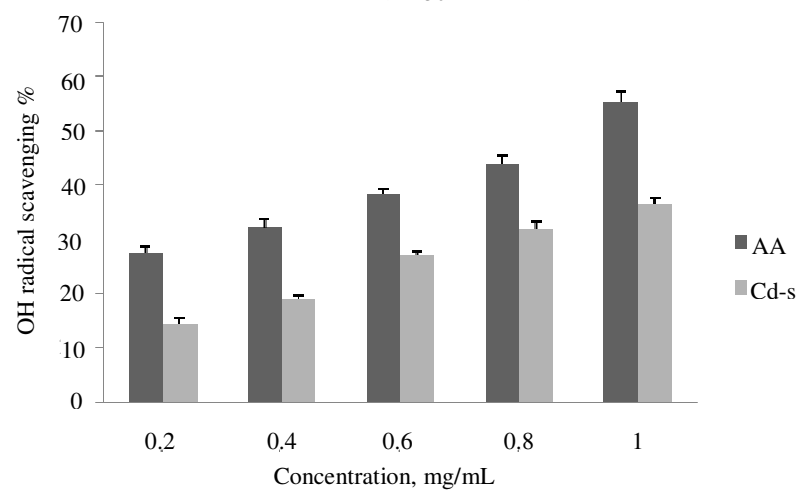

Figure 4. OH radical scavenging ability: tested compound (Cd-S), AA: ascorbic acid) 


\section{Reducing propriety}

The reducing power of new compound $(\mathrm{Cd}-\mathrm{S})$ was assayed according to the method of Pulido et al. ${ }^{26}$ Briefly, a methanolic solution of compound $(\mathrm{Cd}-\mathrm{S})(1 \mathrm{~mL})$ at different concentration $(0.2-1 \mathrm{mg} / \mathrm{mL})$ was mixed with $2.5 \mathrm{~mL}$ of phosphate buffer $(0.2 \mathrm{M})$ and 2.5 $\mathrm{mL}$ of $1 \%$ potassium ferricyanide and incubated at $50{ }^{\circ} \mathrm{C}$ for $20 \mathrm{~min}$. To this mixture, 2.5 $\mathrm{mL}$ of $10 \%$ trichloroacetic acid was added and the mixture was centrifuged at $3000 \mathrm{rpm}$ for $20 \mathrm{~min}$. The upper layer $(2.5 \mathrm{~mL})$ was mixed with $2.5 \mathrm{~mL}$ of deionized water and $0.5 \mathrm{~mL}$ of $0.1 \%$ Ferric chloride and the same treatment was performed to a standard ascorbic acid solution and the absorbance taken at $700 \mathrm{~nm}$. The reducing property was measured using the following equation:

Reducing power $\%=[($ Abs cont - Abs test $) /$ Abs cont $] \times 100$

Where Abs cont $=$ absorbance of the control (reacting mixture without the test sample) and Abs test sample $=$ absorbance of reacting mixture with the test sample.

The results was presented in Figure 5 reported that Cd-S has a slight reducing property to compare to that of ascorbic acid and the percentage in the highest concentration $(1 \mathrm{mg} / \mathrm{mL})$ is AA $49.28 \pm 0.85 \%\left(\mathrm{IC}_{50}=0.88\right)$ and $\mathrm{Cd}-\mathrm{S} 48.76 \pm 0.929 \%\left(\mathrm{IC}_{50}=1.122\right)$.

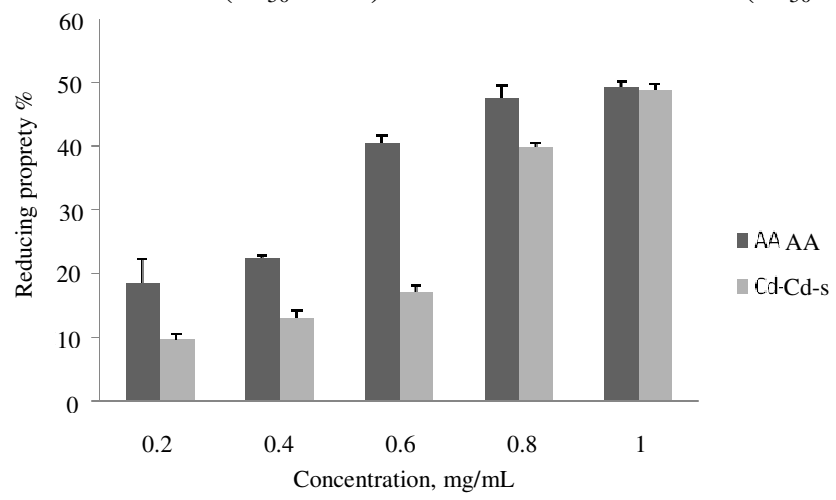

Figure 5. Reducing power assay: tested compound (Cd-S), AA: ascorbic acid)

\section{Conclusion}

CdS nanoparticles with average grain size of about $12 \mathrm{~nm}$ were successfully synthesized by hydrothermal method. The results presented highlight the possible uses of CdS nanoparticles in different biological level of study. Our results aimed to show the antioxidant activity in vitro of new compound (Cd-S). Our data showed that compound complex has an antioxidant character; this is demonstrated by scavenging DPPH radicals, ABTS radicals, hydroxyl radical scavenging and reducing property to that of ascorbic acid.

\section{Acknowledgment}

Conflict of interest statement the authors declare that there is no conflict of interest regarding the publication of this document.

\section{References}

1. Bawendi M G, Steigerwald M L and Brus L E, Annu Rev Phys Chem., 1990, 41, 477 496; DOI:10.1146/annurev.pc.41.100190.002401

2. Alivisatos A P, Science, 1996, 271(5251), 933-937; DOI:10.1126/science.271.5251.933 
3. Medintz I L, Uyeda H T, Goldman E R and Mattoussi H, Nat Mater., 2005, 4, 435-446.

4. Goorsky N D, Thessing J and Peng X G, J Am Chem Soc., 2005, 127(50), 1758617587; DOI:10.1021/ja055557z

5. Pradhan N and Peng X G, J Am Chem Soc., 2007, 129(11), 3339-3347; DOI:10.1021/ja068360v

6. Wang C, Gao X, Ma Q and Su X, J Mater Chem., 2009, 19, 7016-7022; DOI:10.1039/B909546B

7. Shao P, Zhang Q, Li Y and Wang H, J Mater Chem., 2011, 21, 151-156; DOI:10.1039/C0JM01878C

8. Fang Z, Wu P, ZhongX and Yang Y J, Nanotech., 2010, 21(30), 305604; DOI: $10.1088 / 0957-4484 / 21 / 30 / 305604$

9. Aboulaich A, Geszke M, BalanL, Ghanbaja J, Medjahdi G and Schneider R, Inorg Chem., 2010, 49(23), 10940-10948; DOI:10.1021/ic101302q

10. Aboulaich A, Balan L, Ghanbaja J, Medjahdi G, Merlin C and Schneider R, Chem Mater., 2011, 23(16), 3706-3713; DOI:10.1021/cm2012928

11. Geszke M, Murias M, Balan L, Medjahdi G, Korczynski J, Moritz M, Lulek J and Schneider R, Acta Biomater., 2011, 7(3), 1327-1338; DOI:10.1016/j.actbio.2010.10.012

12. Geszke-Moritz M, Clavier G, Lulek J and Schneider R, J Lumin., 2012, 132(4), 987 991; DOI:10.1016/j.jlumin.2011.12.014

13. Rajeshwar K, Tacconi N R and Chentha C R, Chem Mater., 2001, 13(9), 2765-2782; DOI:10.1021/cm010254z

14. Tang H, Yan Mi, Zhang Hui, Xia M and Yang D, Mater Let., 2005, 59(8-9), 10241027; DOI:10.1016/j.matlet.2004.11.049

15. Kumar P, Deep A, Sharma S C and Bharadwaj L M, Anal Biochem., 2012, 421(1), 285-290; DOI:10.1016/j.ab.2011.10.037

16. Kolvin V L, Schlamp M C and Alivisatos A P, Nature, 1994, 370(6488), 354-357; DOI:10.1038/370354a0

17. Klein D L, Roth R, Lim A K L and Alivisatos A P, Nature, 1997, 389, 699; DOI:10.1038/39535

18. Bruchez M, Moronne M, Gin P, Weiss S and Alivisatos A P, Science, 1998, 281(5385), 2013-2016; DOI:10.1126/science.281.5385.2013

19. Warren B E, Chapter 13 INC, New York, 1990, 253.

20. Aruoma O I and Cuppette S L, IL: AOCS Press, 1997.

21. Stadtman E R, Science, 1992, 257(5074), 1220-1224; DOI:10.1126/science. 1355616

22. Wiseman H and Halliwell B, J Bioch., 1996, 313, 17-29; DOI:10.1042/bj3130017

23. Braca A, Tommasi N D, Bari L D, Pizza C, Politi M and Morelli I, J Nat Prod., 2001, 64(7), 892-895; DOI:10.1021/np0100845

24. Pellegrini Re, Proteggente A, Pannala A and Yong M, Rad Biol Med., 1999, 26(9-10), 1231-1237; DOI:10.1016/S0891-5849(98)00315-3

25. Halliwell B, Gutteridge J M C and Aruoma O I, Anal Biochem., 1987, 165(1), 215219; DOI:10.1016/0003-2697(87)90222-3

26. Pulido R, Bravo L and Saura-Calixt F, J Agric Food Chem., 2000, 48(9), 396-402; DOI:10.1021/jf0002995 